\title{
Comparison of direct and indirect determinations of dynamic ventilation rate in a modern dairy free stall barn
}

\author{
Bing Zou ${ }^{1}$, Albert J. Heber ${ }^{2}$, Zhengxiang $\mathrm{Shi}^{3}$, Songhuai $\mathrm{Du}^{{ }^{*}}$, Yaomin $\mathrm{Jin}^{4}$, \\ Teng Teeh Lim $^{5}$ \\ (1. College of Information and Electrical Engineering, China Agricultural University, Beijing 100083 China; \\ 2. Department of Agriculture and Biological Engineering, Purdue University, West Lafayette 47907, USA; \\ 3. College of Water Sources and Civil Engineering, China Agricultural University, Beijing 100083, China; \\ 4. Ministry of Energy, Mines and Petroleum Resources, Victoria V8W 9N3, Canada; \\ 5. College of Agriculture, Food and Natural Resources, University of Missouri, Columbia 65211, USA)
}

\begin{abstract}
Reliable estimation of the ventilation rate (VR) in intensive livestock buildings is necessary for studying building environmental control strategies and predicting indoor air quality and air emissions. As direct air exchange measurements are time-consuming and expensive, it is environmentally inefficient to measure livestock building VR continuously in practice. Hence, indirect VR estimation methods have been widely used in modelling environmental control and air emissions, and also to measure airflow in the field. The accuracy of indirect measurement methods needs to be evaluated by comparing with direct measurements. In this study, the direct and indirect methods of determining hourly and daily mean VRs were applied to a mechanically-ventilated dairy free stall barn monitored by the 24-month National Air Emissions Monitoring Study. The direct method was used to continuously monitor fan rotational speeds, and differential static pressures, coupled with periodic in-situ fan performance assessments, to calculate the VR. The indirect method consisted of estimating the VR using $\mathrm{CO}_{2}$ concentration measurements and the $\mathrm{CO}_{2}$ mass balance method. The average daily and hourly means (mean $\pm \mathrm{SD}$ ) of directly measured barn ventilation rates for two years were $(246 \pm 73) \mathrm{m}^{3} / \mathrm{s}$ and $(245 \pm 77) \mathrm{m}^{3} / \mathrm{s}$, respectively. The average daily and hourly means (mean $\pm \mathrm{SD}$ ) of barn ventilation rates estimated by the $\mathrm{CO}_{2}$ mass balance method were $(287 \pm 93.4) \mathrm{m}^{3} / \mathrm{s}$ and $(287 \pm 118) \mathrm{m}^{3} / \mathrm{s}$, respectively. Correlation analyses showed a strong correlation between the indirect $\mathrm{CO}_{2}$ mass balance method and direct measurement methods ( $r=0.93$ for daily means and $r=0.85$ for hourly means).
\end{abstract}

Keywords: dynamic ventilation rate, modern dairy, free stall barn, carbon dioxide, mass balance, dairy cow, direct and indirect determination, comparison

DOI: $10.25165 / j$.jjabe.20201306.5767

Citation: Zou B, Heber A J, Shi Z X, Du S H, Jin Y, Lim T T. Comparison of direct and indirect determinations of dynamic ventilation rate in a modern dairy free stall barn. Int J Agric \& Biol Eng, 2020; 13(6): 41-46.

\section{Introduction}

Ventilation systems in livestock housing serve to maintain a comfortable and safe environment for animals. They continuously remove heat, moisture, and gases created by the livestock, and replenish the oxygen supply by bringing in drier and cooler outside air. Specific gases removed include ammonia $\left(\mathrm{NH}_{3}\right)$, and hydrogen sulphide $\left(\mathrm{H}_{2} \mathrm{~S}\right)$, which can be harmful to both animal and human health if allowed to reach unsafe concentrations $^{[1]}$. Thus, proper ventilation design is necessary for livestock houses. Mechanical ventilation systems force air through livestock buildings typically with exhaust fans ${ }^{[2]}$. As

\section{Received date: 2020-03-08 Accepted date: 2020-07-29}

Biographies: Bing Zou, PhD candidate, research interests: agricultural electrification and automation, Email: bingbingliang@126.com; Albert J. Heber, $\mathrm{PhD}$, Professor, research interests: agricultural engineering, Email: heber@purdue.edu; Zhengxiang Shi, PhD, Professor, research interests: livestock and poultry breeding technology and environment, Email: shizhx@cau.edu.cn; Yaomin Jin, PhD, research interests: environmental engineering, Email: biofiltration@gmail.com; Teng Teeh Lim, PhD, Extension Associate Professor, research interests: assessment of dust, odor and gas emissions of agriculture facilities, Email: limt@missouri.edu.

*Corresponding author: Songhuai Du, PhD, Professor, research interests: agricultural electrification and automation. China Agricultural University, Beijing 100083, China. Tel: +86-10-62736750, Email: songhuaidu@cau.edu.cn. compared with natural ventilation, mechanically-ventilated buildings are more expensive to construct and operate ${ }^{[3]}$. However, mechanical ventilation provides improved environmental control in livestock buildings. Dynamic modelling of thermal environment, indoor air quality, and pollutant emissions require accurate estimations of real-time VR.

The VR in livestock buildings can be determined with either direct measurements or indirect methods. Indirect methods include heat balance, moisture balance, and carbon dioxide balance methods ${ }^{[4]}$. As for naturally ventilated buildings, indirect methods are particularly appropriate ${ }^{[5]}$, because measurements are particularly complex and expensive. Edouard et al. compared $\mathrm{CO}_{2-}$ and $\mathrm{SF}_{6}$-based tracer gas methods for estimating VR in a naturally ventilated dairy barn and the results showed the $\mathrm{CO}_{2}$ mass balance method resulted in 10\%-12\% lower VR compared with $\mathrm{SF}_{6}$-based measurements ${ }^{[6]}$.

Samer et al. ${ }^{[7]}$ used the $\mathrm{CO}_{2}$ and moisture $\left(\mathrm{H}_{2} \mathrm{O}\right)$ balance methods, and the tracer gas technique (TGT) to indirectly measure VR in a naturally ventilated animal building. Blanes and Pedersen ${ }^{[4]}$ examined the agreement between ventilation flow measured in a pig house over a period of $41 \mathrm{~d}$ and found that all three methods can give reasonably good estimations of VR on an hourly basis. Li et al. ${ }^{[8]}$ compared laying hen house VRs obtained by direct measurements and indirectly by a $\mathrm{CO}_{2}$ balance and the results indicated that ventilation rates estimated by the indirect method were not 
significantly different $(p>0.20)$ from those determined by direct measurements when the averaging or integration time intervals were $2 \mathrm{~h}$ or longer. Estellés et al. ${ }^{[9]}$ recommended $\mathrm{CO}_{2}$ balance for determining ventilation rates in fattening rabbit buildings based on field tests. Liu et al. ${ }^{[10]}$ summarized baseline data on $\mathrm{CO}_{2}$ production from various animal species and determined uncertainties of the $\mathrm{CO}_{2}$ balance approach for estimating animal house VR. Based on their results, when using the $\mathrm{CO}_{2}$ balance approach to estimate VR for buildings housing broilers, laying hens, swine, and steers, a minimum of ten replicate measurements is required to achieve a margin of error less than $20 \%$ in modelled VR with $95 \%$ confidence.

Direct measurements of VR in mechanically ventilated livestock buildings consists of measuring exhaust fan operations and rotational properties and differential static pressure, coupled with in-situ fan airflow calibrations ${ }^{[11]}$. Additionally, air speed measurements can be used ${ }^{[12]}$. Rosa et al. $^{[13]}$ used hot wire anemometry, fan rotational speed monitoring, and the $\mathrm{CO}_{2}$ mass balance method to assess VR in a mechanical ventilated laying hen facility. A simple fan operation (on/off) monitoring system at a broiler farm with single speed fans was described by Calvet et al. ${ }^{[14]}$. It consisted of a low voltage DC circuit connected to the auxiliary contacts of the fan motor control relays. However, these direct methods require relatively complex equipment installation and continuous monitoring parameters, which are time-consuming and expensive.

This study based on comprehensive measurements conducted at a dairy farm in Indiana for the National Air Emissions Monitoring Study (NAEMS). The NAEMS was designed to continuously and simultaneously collect air pollutant emission data for two years at various barns in the $\mathrm{USA}^{[15]}$. This study focused on the VR determinations at one of the dairy free stall barns at the Indiana site. This study continued to measure the ventilation rate of the cowshed for two consecutive years, covering the four seasons of spring, summer, autumn and winter.

The direct VR measurement method and the $\mathrm{CO}_{2}$ mass balance method for measuring daily average ventilation rate and the hourly average ventilation rate were applied and compared to explore the feasibility and accuracy of estimating mechanical ventilation rate using indirect measurement methods.

\section{Materials and methods}

\subsection{Description of the dairy barn}

The monitored commercial dairy farm was located in Indiana, USA. Free stall barns 1 and 2 (Figure 1) were monitored in this study ${ }^{[16]}$. The milking centre (MC) was connected directly to barn 1 (Figure 1).

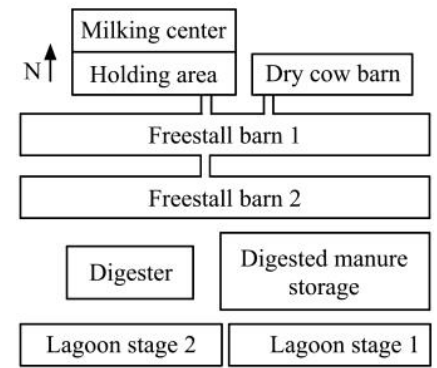

Figure 1 Facility layout with barns 1 and 2 monitored

The exhaust fan airflows in the west half of each $472 \mathrm{~m} \times 29 \mathrm{~m}$ barns were monitored. The milking centre consisted of a holding area and a milking parlour. Manure was removed from the free stall barns and the milking centre by scraping and flushing, respectively ${ }^{[16]}$. The free stall barns were tunnel ventilated with fresh air entering through large evaporative cooling pads (cool cells) in the centre of the sidewalls and exhausting through 28 fans at each end of the barns and 12 sidewall fans as shown in Figure 2. Based on inside barn temperature, the number of fans operating ranged from 14 fans when $T<7.8^{\circ} \mathrm{C}$ to all 76 fans when $T>17.8^{\circ} \mathrm{C}$.

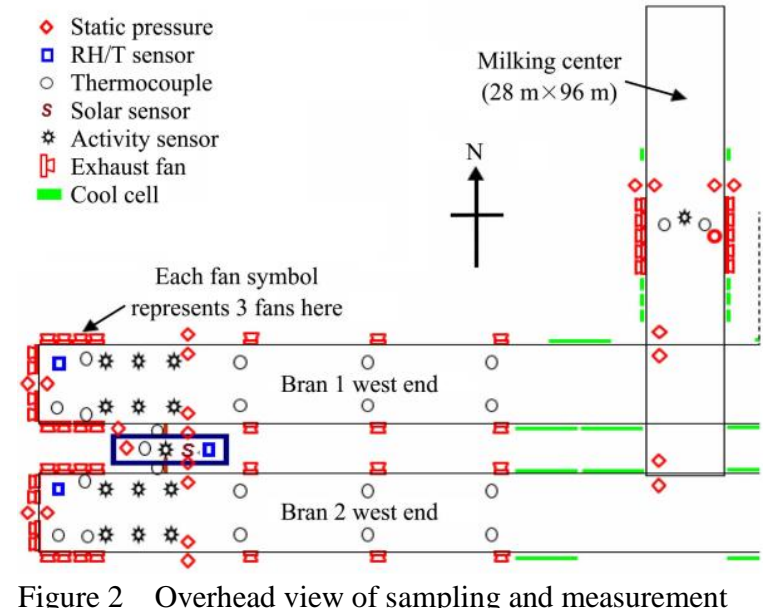

Figure 2 Overhead view of sampling and measurement locations $^{[16]}$

As shown in Figure 2, the outside temperature was measured by a solar shielded capacitance-type relative humidity and temperature probe near the barn on a $10 \mathrm{~m}$ tower. Inside exhaust temperatures were measured with relative humidity and temperature sensor at one exhaust location and thermocouples at nine other exhaust locations $^{[16]}$.

\subsection{Direct measurement of VR}

The data acquisition system monitored the operation of each ventilation stage and the rotational speeds of 23 representative fans per barn ${ }^{[16]}$. Differential static pressures were measured across the north, west, and south walls by Lim et al. ${ }^{[16]}$. In-field measurements of fan airflow measurements were conducted with a portable fan tester (Fan Assessment Numeration System, University of Kentucky, Lexington, KY). Fan rotational speed and operational status was monitored using a magnetic Hall-effect sensor (speed sensor) installed on each continuously-operated fan. The speed sensors were mounted to detect the rotational speed in revolutions per minute $(\mathrm{r} / \mathrm{min})$ of the fan pulley. The digital signal from the speed sensor was converted into a frequency measurement with a counter module in the data acquisition system. Static pressure was measured across the north, west, and south walls of B1 and B2 with differential static pressure sensors (Model 260, Setra Systems, Boxborough, MA). The outside ports were located against the outside wall near the ventilation fans. Static pressure in the OFIS was measured with the same type of sensor.

Equations to calculate fan airflows based on static pressure and fan speeds were developed from field data resulting from 278 fan tests. According to Lim et al. ${ }^{[16]}$, the minute-by-minute VR of the free stall barn was calculated as the sum of the individual fan airflows (Figure 2).

\subsection{Indirect estimation of VR}

The $\mathrm{CO}_{2}$ balance method is the most commonly used method for indirectly estimating the ventilation rate of livestock buildings ${ }^{[5]}$ The principle of the method is to measure the inlet and outlet concentrations of $\mathrm{CO}_{2}$ in the livestock buildings and calculate the barn ventilation rate based on a $\mathrm{CO}_{2}$ mass balance ${ }^{[9]}$. The $\mathrm{CO}_{2}$ in dairy free stall barns is produced by the animals and the manure ${ }^{[17]}$. Since the manure alleys were scraped three times a day in these 
barns, the $\mathrm{CO}_{2}$ released from the manure was considered negligible. With the assumption that all $\mathrm{CO}_{2}$ emissions were from cow respiration, the VR was calculated with Equation (1).

$$
V R_{\mathrm{CO}_{2}}=\frac{P_{\mathrm{CO}_{2}}}{\left[\mathrm{CO}_{2}\right]_{e}-\left[\mathrm{CO}_{2}\right]_{i}}
$$

where, $V R_{\mathrm{CO}_{2}}$ is the VR based on the $\mathrm{CO}_{2}$ balance method, $\mathrm{m}^{3} / \mathrm{h}$; $P_{\mathrm{CO}_{2}}$ is the $\mathrm{CO}_{2}$ production rate, $\left.\mathrm{mL} / \mathrm{s}\right) ;\left[\mathrm{CO}_{2}\right]_{e}$ and $\left[\mathrm{CO}_{2}\right]_{i}$ are $\mathrm{CO}_{2}$ concentrations of exhaust and inlet air, ppm.

Animal $\mathrm{CO}_{2}$ is derived from its energy metabolism rate, which is related to feed intake and composition. Since the $\mathrm{CO}_{2}$ mass balance method is based on the principle of indirect animal calorimetry, the following equation was obtained ${ }^{[18]}$ :

$$
P_{\mathrm{CO}_{2}}=\frac{\Phi}{\frac{16.18}{R Q}+5.02}
$$

where, $\Phi$ is the total cow heat production rate, W/cow; $R Q$ is the respiratory quotient.

The respiratory quotient (RQ) is the ratio of $\mathrm{CO}_{2}$ production over $\mathrm{O}_{2}$ consumption. The RQ is related to the metabolic rate, feed intake, and individual status of the animals ${ }^{[19]}$. Derno et al. ${ }^{[20]}$ constructed and validated a new facility for continuous respiration measurements and found that RQ for dairy cows ranged from 0.99 to $1.01^{[20]}$. Aubry and $\mathrm{Yan}^{[21]}$ used a large respiration calorimeter dataset ( $n=987$ from 30 experiments) and RQ ranged from 0.60 to $1.28^{[21]}$. Machado et al. ${ }^{[22]}$ conducted a validation study using a respiratory system containing four climate-controlled chambers. Twelve lactating dairy cattle were tested and RQ ranged from 1.05 to $1.17^{[23]}$. An RQ of 1.1 was assumed for the current study.

It is expected that cow weight, milk production, feed intake, and ambient temperature directly influences total heat production rate $^{[24]}$, and the total heat production rate $\Phi$ of dairy cows at $20^{\circ} \mathrm{C}$ is as follows:

$$
\Phi=5.6 \times m^{0.75}+22 \times Y_{1}+1.6 \times 10^{-5} \times P^{3}
$$

where, $\Phi$ is the cow's total heat production rate at $20^{\circ} \mathrm{C}, \mathrm{W} ; Y_{1}$ is the milk production, $\mathrm{kg} / \mathrm{d} ; m$ is the cow body mass, $\mathrm{kg} ; P$ is the number of days of pregnancy.

Daily milk production was obtained from the producer's farm records. Since all the dairy cows in the measured barn were lactating, the factors with statistically significant effects on body weight are year, age, season of calving, and lactation stage ${ }^{[25]}$. An average body mass of $635 \mathrm{~kg}$ was the producer's best estimate. Based on a $60 \mathrm{~d}$ dry period, a $283 \mathrm{~d}$ gestation period, and an average $83 \mathrm{~d}$ to conception for a total of $365 \mathrm{~d}$, the cube root average $P$ was $127 \mathrm{~d}$. Therefore, the geometric average of $127 \mathrm{~d}$ was selected for days of pregnancy.

The total heat production $\Phi^{*}$ at different temperatures above $20^{\circ} \mathrm{C}$ are calculated with Equation (4) ${ }^{[24]}$.

$$
\Phi^{*}=\Phi+0.004 \times \Phi(20-T)
$$

where, $T$ is the air temperature, ${ }^{\circ} \mathrm{C} ; \Phi^{*}$ is the total heat production at temperature $T, \mathrm{~W} / \mathrm{cow} ; \Phi$ is the total heat production at temperature of $20^{\circ} \mathrm{C}, \mathrm{W} /$ cow. The $\mathrm{CO}_{2}$ production rate was therefore calculated from Equations (2)-(4).

The inlet and outlet concentrations of $\mathrm{CO}_{2}$ of air sampled from the barn air inlet and outlet were measured with a photoacoustic infrared multi-gas monitor ${ }^{[16]}$. Multipoint calibrations (MPCs) using purified air (CEM zero-grade Cat. \#AIO.OCE-T, Praxair, Indianapolis, IN) and three span concentrations were conducted five times to assess linearity after maintenance or replacement of the analyser. All MPCs used $\mathrm{CO}_{2}$ calibration gases (1100 ppm, $3000 \mathrm{ppm}$ and $5000 \mathrm{ppm}$; or $530 \mathrm{ppm}, 1070 \mathrm{ppm}$ and $1600 \mathrm{ppm}$ ), delivered via a challenging line using a six-port gas dilutor (Model 4040, Environics, Tolland, CT).

Due to different animal behaviour (feeding, moving, resting, etc.), animal activity varies significantly. Carbon dioxide production is related to animal activity, and therefore animal activity is an important factor for calculating $\mathrm{CO}_{2}$ balance over time intervals shorter than $24 \mathrm{~h}^{[26]}$. Animal activity was measured with passive infrared motion detectors at three locations near the west end of the barn (Figure 2).

\section{Results and discussion}

\subsection{Environmental conditions}

During the 2-year experimental period, the daily mean outside temperatures ranged from $-22.4^{\circ} \mathrm{C}$ to $29.4^{\circ} \mathrm{C}$ while the average daily mean ambient temperature was $9.6^{\circ} \mathrm{C}$. Daily mean inside temperature of barn 1 ranged from $-9.9^{\circ} \mathrm{C}$ to $26.4^{\circ} \mathrm{C}$ and averaged $11^{\circ} \mathrm{C}$ (Figure 3).

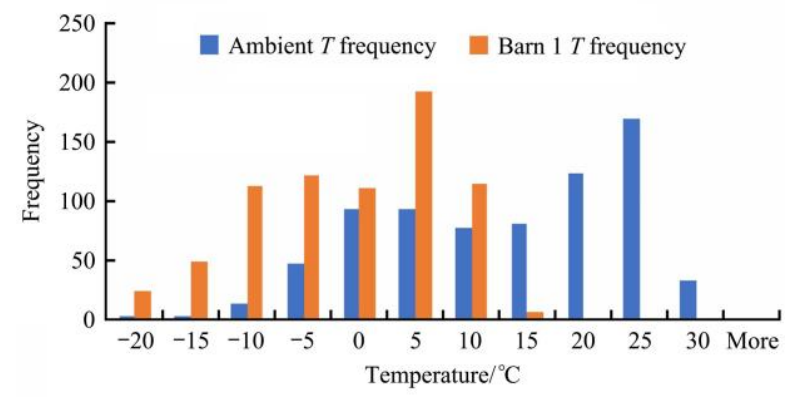

Figure 3 Temperature distribution inside and outside of Barn 1

\subsection{Measured VR}

The daily mean barn and ambient temperatures are plotted in Figure 4. The overall average daily mean VR $($ mean \pm SD) was $(200 \pm 58) \mathrm{m}^{3} / \mathrm{s}$. The daily mean VR ranged from $68 \mathrm{~m}^{3} / \mathrm{s}$ in winter to $286 \mathrm{~m}^{3} / \mathrm{s}$ in summer. The barn VR was higher during the warm season due to the elevated heat removal requirements in summer.

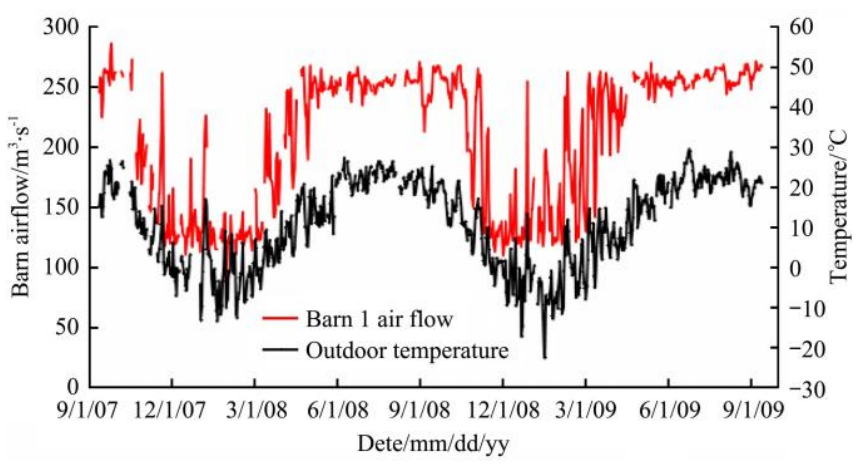

Figure 4 Ambient temperature and VR for barn 1

\subsection{Estimated VR by $\mathrm{CO}_{2}$ mass balance}

As stated earlier, it was assumed that all $\mathrm{CO}_{2}$ produced in the barn was derived from cattle respiration. During the 29-month test, the average measured $\mathrm{CO}_{2}$ production ranged from $0.16 \mathrm{~m}^{3} /\left(\mathrm{h} \cdot \mathrm{hpu}\right.$ ) to $0.22 \mathrm{~m}^{3} /(\mathrm{h} \cdot \mathrm{hpu}$ ) (where $1 \mathrm{hpu}=1000 \mathrm{~W}$ of total heat produced by the animals at $20^{\circ} \mathrm{C}$ ) and the average calculated $\mathrm{CO}_{2}$ production was $0.183 \mathrm{~m}^{3} /(\mathrm{h} \cdot \mathrm{hpu})$. In 1998 , Pedersen et al. observed a value of $0.185 \mathrm{~m}^{3} /(\mathrm{h} \cdot \mathrm{hpu})$ for total $\mathrm{CO}_{2}$ production that resulted in good agreement between ventilation rate calculated from the $\mathrm{CO}_{2}$ balance and ventilation rate measured in animal houses $^{[27]}$. Also, a value of $0.185 \mathrm{~m}^{3} /(\mathrm{h} \cdot \mathrm{hpu})$ was recommended for dairy cows based on measurements in respiration chambers ${ }^{[17,28]}$.

During the experimental period, the mean inlet $\mathrm{CO}_{2}$ concentration was $(459 \pm 39.6) \mathrm{ppm}$, which was greater than the 
atmospheric mean $\mathrm{CO}_{2}$ concentration (403 ppm) reported by the World Meteorological Organization ${ }^{[29]}$. The reason for the elevated inlet concentration is attributed to the re-entry of the exhaust air from this and other barns at the farm. Meanwhile, the average $\mathrm{CO}_{2}$ concentration of the exhaust air was $(796 \pm 154) \mathrm{ppm}$. The difference between the overall average inlet and exhaust air $\mathrm{CO}_{2}$ concentrations was greater than $200 \mathrm{ppm}$, which is the threshold for reliable application of the $\mathrm{CO}_{2}$ balance method ${ }^{[30]}$. The maximum daily mean $\mathrm{CO}_{2}$ concentration of $1661 \mathrm{ppm}$ was measured in winter when ventilation rate was near the minimum capacity of the building, causing greater $\mathrm{CO}_{2}$ concentration inside the barn ${ }^{[13]}$. The minimum daily mean concentration of $582 \mathrm{ppm}$ occurred in warm weather. This seasonal pattern is described by an inverse relationship between $\mathrm{CO}_{2}$ concentration and VR (Figure 6). This pattern was also observed by Xin et al. in a broiler facility $^{[5]}$.

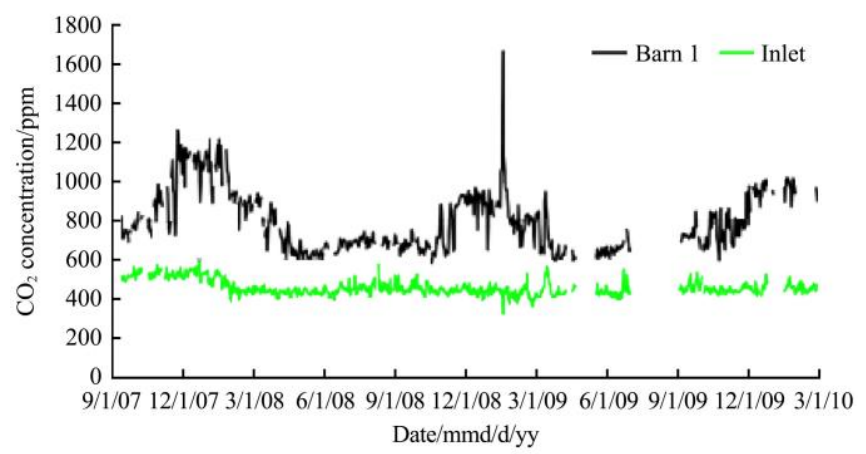

Figure $5 \quad \mathrm{CO}_{2}$ concentrations inside and outside the barn in two years

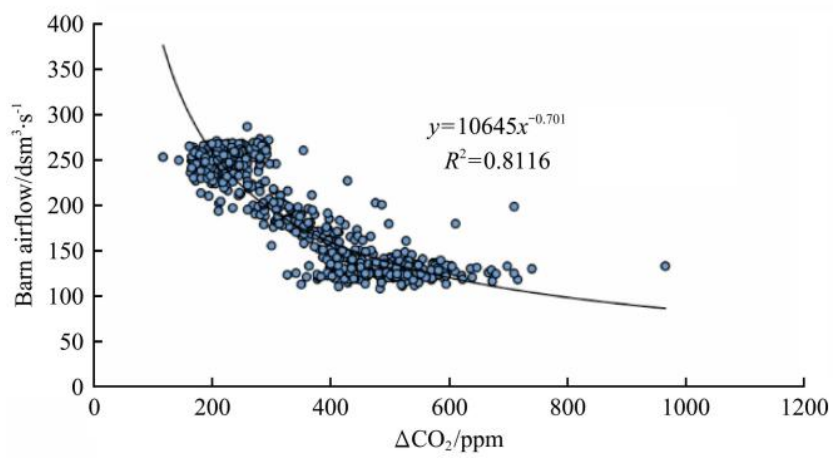

Figure 6 Relation of directly measured ventilation rate and $\mathrm{CO}_{2}$ concentration differences between the outlet and the inlet, daily for Barn 1

According to the measured indoor and outdoor carbon dioxide concentrations and ventilation rate, the relationship between them is shown in Figure 6. With the increase in ventilation rate, the concentration difference of carbon dioxide is decreasing. The concentration difference in carbon dioxide is mainly between 200-700 ppm.

Animal activity influences respiration rate, which in turn affects the production of $\mathrm{CO}_{2}$. When it comes to hourly VR estimations, the diurnal animal activity patterns must be considered to adjust the VR throughout the day, while maintaining the daily mean. In this study, the animal activity patterns showed seasonal and diurnal variations (Figure 7). The diurnal variations are related to milking and feeding schedules ${ }^{[31]}$. Milking occurred continuously but any individual cow would have a schedule involving being milked and fed three times a day. For the small group of cows that were monitored by the activity sensors, the morning feeding session started at about 11:00 and the morning activity peak was measured one hour later at about 12:00 when milked. Similarly, the afternoon feeding session started at about 18:30 and the afternoon activity peak was measured at about 19:30. When milked, the daily activity of the cows was strongly related to the average indoor air temperature. In general, the cows were more active when it got colder ${ }^{[32]}$. Usually, the coldest time occurred after midnight, also, in hot weather, the cool cells were added, that is why there was an activity peak measured at about 3:00.

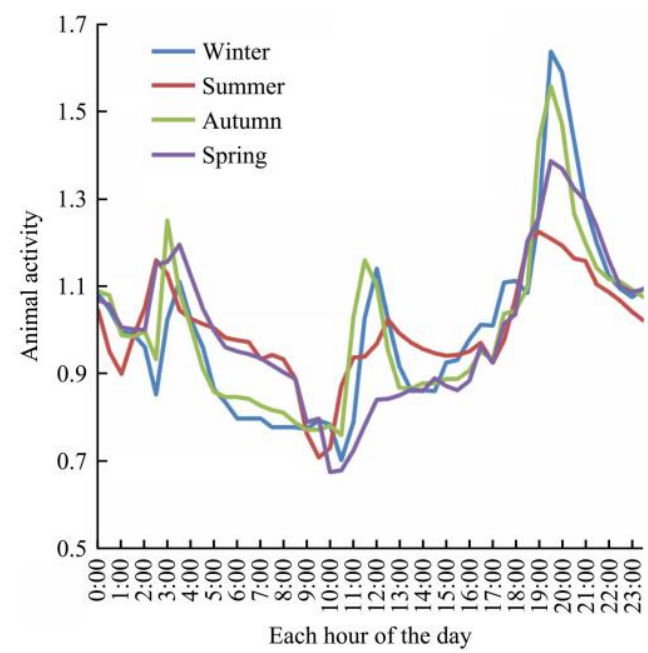

Figure 7 Seasonal and diurnal variations of dairy cow activity

\subsection{Comparison between measured and predicted ventilation} flow

The daily mean measured and predicted VR using the $\mathrm{CO}_{2}$ balance approach are compared in Figure 8. The regression analysis shows that there was a strong correlation between the $\mathrm{CO}_{2}$ balance method and the direct measurement method $\left(R^{2}=0.870\right.$, $P=0.014$ ) (Figure 9). Due to a relatively constant average body weight of the dairy cow herd during the test, the predicted $\mathrm{CO}_{2}$ production rates had little variation. The uncertainties in the measured $\mathrm{CO}_{2}$ concentrations contributed to uncertainties in predicted VR. When differences in $\mathrm{CO}_{2}$ concentrations between exhaust and inlet air were relatively small, even small uncertainties in measured $\mathrm{CO}_{2}$ concentrations can result in huge errors in predicted $\mathrm{VR}^{[10]}$. Although the average difference in $\mathrm{CO}_{2}$ concentrations was higher than the applicable threshold (200 ppm), the concentration differences during hot weather were less than $200 \mathrm{ppm}$. Based on observed standard deviations, when using the $\mathrm{CO}_{2}$ balance approach to estimate VR for dairy cows with $95 \%$ confidence, a minimum of 12 replicate measurements is required to achieve a margin of error less than $20 \%$ in predicted VR. In general terms, the daily mean $\mathrm{CO}_{2}$ balance VR was less sensitive in the warmest $\left(>25^{\circ} \mathrm{C}\right)$ and coldest $\left(<17^{\circ} \mathrm{C}\right)$ conditions compared with direct methods.

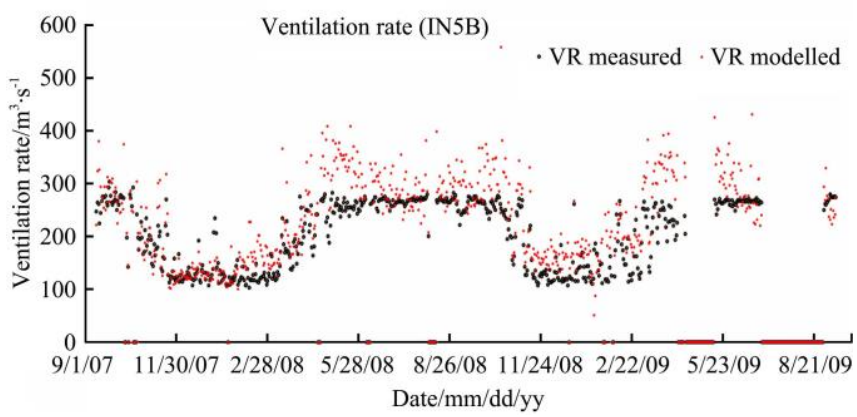

Figure 8 Predicted daily mean ventilation rates compared with daily mean measured VR 


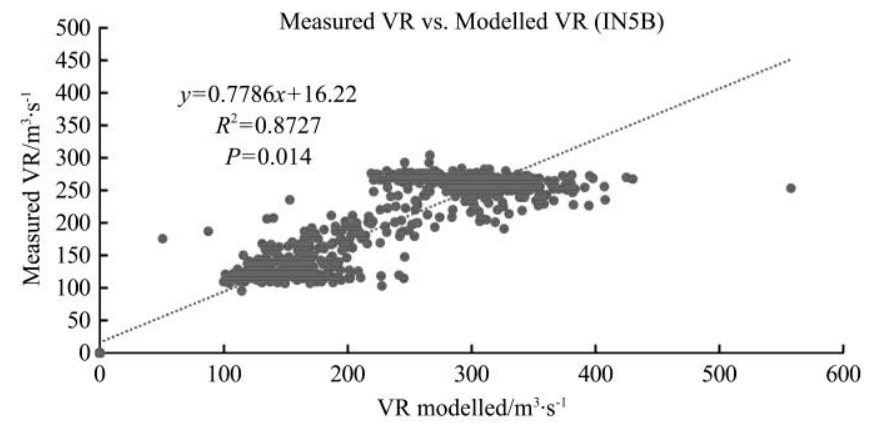

Figure 9 Regression of measured vs predicted daily mean ventilation rates

Taking animal activity into account, the hourly mean measured and predicted VR using the $\mathrm{CO}_{2}$ balance are presented in Figure 10. The regression analysis showed a strong correlation between the $\mathrm{CO}_{2}$ balance method and the direct measurement method $\left(R^{2}=0.725\right.$, $p<0.001$ ), as shown in Figure 11. The decline in correlation was due to an increase in the volume of data and the error introduction by animal activity measurements.

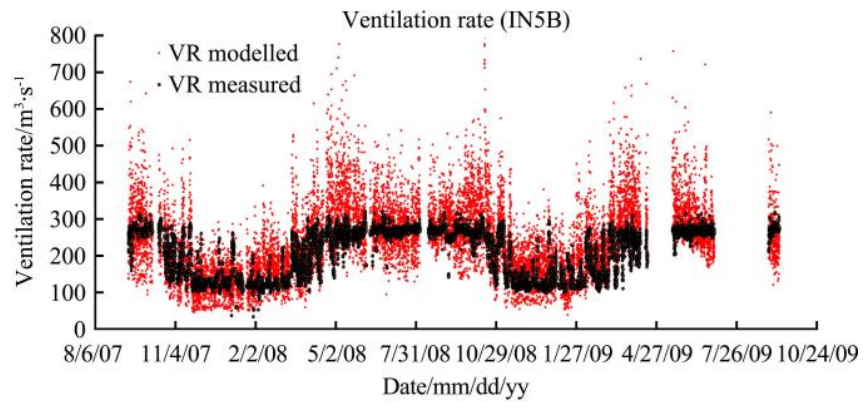

Figure 10 Daily average hourly mean predicted ventilation rates compared with daily average hourly mean measured ventilation rates

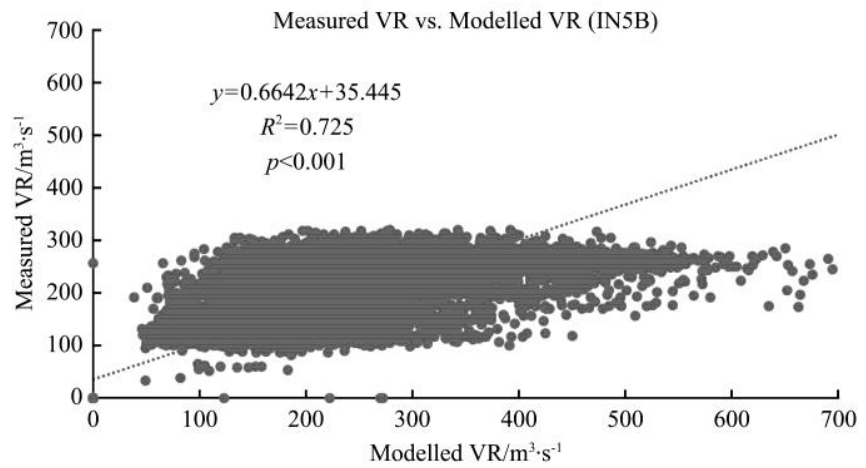

Figure 11 Regression of measured vs predicted daily average hourly mean ventilation rates

\section{Conclusions}

In this work, a comparison between measured ventilation rates in a mechanical ventilated dairy free stall barn over two years, and the ventilation rate calculated using a $\mathrm{CO}_{2}$ mass balance method was conducted. Results indicated that ventilation flow calculated from the $\mathrm{CO}_{2}$ mass balance was in good agreement with the measurements and can therefore serve as a reliable tool for predicting the VR in dairy free stall barns. Specific conclusions are as follows:

1) Daily mean ventilation rates estimated by the $\mathrm{CO}_{2}$ balance was, on average, $13.40 \%$ higher than the average measured VR. The predicted hourly mean VR was, on average, $8.34 \%$ higher than the average hourly mean measured VR.
2) Dairy cow activity signals exhibited diurnal and seasonal patterns. The production of carbon dioxide in the dairy barn showed similar patterns. When using the carbon dioxide balance method to estimate the hourly ventilation rate, it is necessary to adjust the animal activity.

3) The coefficient of determinations $\left(r^{2}\right)$ between measured and estimated daily and hourly mean ventilation airflow rates were 0.870 and 0.725 , respectively.

\section{Acknowledgements}

The authors acknowledge the National Air Emissions Monitoring Study as the source of field data. Any queries relating to the raw data should be directed to the authors.

\section{Nomenclature}

\begin{tabular}{lll}
\hline Symbol & Description & Unit \\
\hline$T$ & Barn temperature & ${ }^{\circ} \mathrm{C}$ \\
$V R$ & Ventilation rate & $\mathrm{m}^{3} \cdot \mathrm{s}^{-1}$ \\
NAEMS & National Air Emissions Monitoring Study & \\
$R Q$ & Respiratory quotient & \\
$P$ & Number of days of pregnancy & \\
$\mathrm{MPCs}$ & Multipoint calibrations & \\
$V R_{\mathrm{CO}_{2}}$ & VR based on the CO balance method & $\mathrm{m} \cdot \mathrm{h}^{-1}$ \\
$P_{\mathrm{CO}_{2}}$ & $\mathrm{CO}_{2}$ production rate & $\mathrm{mL} \cdot \mathrm{s}^{-1}$ \\
{$\left[\mathrm{CO}_{2}\right]_{e}$} & $\mathrm{CO}_{2}$ concentrations of exhaust air & $\mathrm{ppm}$ \\
{$\left[\mathrm{CO}_{2}\right]_{I}$} & $\mathrm{CO}_{2}$ concentrations of inlet air & $\mathrm{ppm}$ \\
$\Phi$ & Total cow heat production rate & $\mathrm{W} \cdot \mathrm{cow}^{-1}$ \\
$M$ & Cow body mass & $\mathrm{kg}$ \\
$Y_{1}$ & Milk production & $\mathrm{kg} \cdot \mathrm{d}^{-1}$ \\
${ }^{*}$ & Total heat production at temperature $T$ & $\mathrm{~W} \cdot \mathrm{cow}^{-1}$ \\
\hline
\end{tabular}

\section{[References]}

[1] Copeland C. Air quality issues and animal agriculture: A primer. In: CRS Report for Congress, 2010; pp.13-45.

[2] Kundert W R. Ventilation fan control. 1994; United States Patent 5364026.

[3] Keenan J D, Amundsen R N. Assessment of waste heat utilization technologies: Overview. Journal of Environmental Systems, 1990; 19(2): 95-114.

[4] Blanes V, Pedersen S. Ventilation flow in pig houses measured and calculated by carbon dioxide, moisture and heat balance equations. Biosystems Engineering, 2005; 92(4): 483-493.

[5] Xin H, Li H, Gates R S, Overhults D G, Earnest Jr J W. Use of $\mathrm{CO}_{2}$ concentration difference or $\mathrm{CO}_{2}$ balance to assess ventilation rate of broiler houses. Transactions of the ASABE, 2009; 52(4): 1353-1361.

[6] Edouard N, Mosquera J, van Dooren H J, Mendes L B, Ogink N W. Comparison of $\mathrm{CO}_{2}$ - and $\mathrm{SF}_{6}$-based tracer gas methods for the estimation of ventilation rates in a naturally ventilated dairy barn. Biosystems Engineering, 2016; 149: 11-23.

[7] Samer M, Ammon C, Loebsin C, Fiedler M, Berg W, Sanftleben P, et al Moisture balance and tracer gas technique for ventilation rates measurement and greenhouse gases and ammonia emissions quantification in naturally ventilated buildings. Building and Environment, 2012; 50: 10-20.

[8] Li H, Xin H, Liang Y, Gates R S, Wheeler E F, Heber A J. Comparison of direct vs. indirect ventilation rate determinations in layer barns using manure belts. Transactions of the ASAE, 2005; 48(1): 367-372.

[9] Barber F E, Fernandez N, Torres A, Sanz S C. Use of CO2 balances to determine ventilation rates in a fattening rabbit house. Spanish Journal of Agricultural Research, 2011(3): 713-720.

[10] Liu Z, Powers W, Harmon J. Estimating ventilation rates of animal houses through $\mathrm{CO}_{2}$ balance. Transactions of the ASABE, 2016; 59(1): 321-328.

[11] Hoff S J, Bundy D S, Nelson M A, Zelle B C, Jacobson L D, Heber A J, et al. 
Real-time airflow rate measurements from mechanically ventilated animal buildings. Journal of the Air \& Waste Management Association, 2009; 59(6): 683-694.

[12] Chen L, Lim T T, Jin Y, Heber A J, Ni J Q, Cortus E L, et al. Ventilation rate measurements at a mechanically-ventilated pig finishing quad barn. Biosystems Engineering, 2014; 121: 96-104.

[13] Rosa E, Arriaga H, Calvet S, Merino P. Assessing ventilation rate measurements in a mechanically ventilated laying hen facility. Poultry Science, 2019; 98(3): 1211-1221.

[14] Calvet S, Cambra-López M, Blanes-Vidal V, Estellés F, Torres A. Ventilation rates in mechanically-ventilated commercial poultry buildings in Southern Europe: Measurement system development and uncertainty analysis. Biosystems Engineering, 2010; 106(4): 423-432.

[15] Heber A J, Bogan B W, Ni J Q, Lim T T, Ramirez-Dorronsoro J C, Cortus E $\mathrm{L}$, et al. The national air emissions monitoring study: overview of barn sources. In: Livestock Environment VIII, 31 August-4 September 2008, Iguassu Falls: ASABE, 2009. doi: 10.13031/2013.25499.

[16] Lim T T, Ni J Q, Heber A J, Jin Y. Applications and calibrations of the fans and traverse methods for barn airflow rate measurement. In: International Symposium on Air Quality and Manure Management for Agriculture Conference Proceedings, 13-16 September 2010, Dallas: ASABE, 2010. doi: $10.13031 / 2013.32629$

[17] Pedersen S, Blanes-Vidal V, Jørgensen H, Chwalibog A, Haeussermann A, Heetkamp M, et al. Carbon dioxide production in animal houses: A literature review. Agricultural Engineering International: CIGR Journal, 2008; 10: 1-19.

[18] Brouwer E. Report of sub-committee on constants and factors. In: Proceedings of the 3rd symposium on energy metabolism of farm animals, 1965.

[19] Van Ouverkerk E, Pedersen S. Application of the carbon dioxide mass balance method to evaluate ventilation rates in livestock buildings. Proc. XII CIGR World Congress on Agricultural Engineering, 1994; 1: 516-529.

[20] Derno M, Elsner H G, Paetow E A, Scholze H, Schweigel M. A new facility for continuous respiration measurements in lactating cows. Journal of Dairy Science, 2009; 92(6): 2804-2808.

[21] Aubry A, Yan T. Meta-analysis of calorimeter data to establish relationships between methane and carbon dioxide emissions or oxygen consumption for dairy cattle. Animal Nutrition, 2015; 1(3): 128-134.
[22] Machado F, Tomich T, Ferreira A, Cavalcanti L, Campos M, Paiva C, et al A facility for respiration measurements in cattle. Journal of Dairy Science, 2016; 99(6): 4899-4906.

[23] Machado F S, Tomich T R, Ferreira A L, Cavalcanti L F, Campos M M, Paiva C A, et al. Technical note: A facility for respiration measurements in cattle. Journal of Dairy Science, 2016; 99(6): 4899-4906

[24] Pedersen S, Sällvik K J R C B, Danish institute of agricultural sciences: International commission of agricultural engineering, section II. Denmark. CIGR 4th Report of Working Group on Climatization of Animal Houses Heat and Moisture Production at Animal and House Levels, 2002.

[25] Hietanen H, Ojala M. Factors affecting body weight and its association with milk production traits in Finnish Ayrshire and Friesian cows. Acta Agriculturae Scandinavica, Section A-Animal Science, 1995; 45(1): 17-25.

[26] Pedersen S, Rom H B. Diurnal variation in heat production from pigs in relation to animal activity. Eurinfo Le Magazine De La Representation De La Ce En Belgique, 1998; 31(1): 10-13.

[27] Pedersen S, Takai H, Johnsen J O, Metz J, Koerkamp P G, Uenk G, et al. A comparison of three balance methods for calculating ventilation rates in livestock buildings. Journal of Agricultural Engineering Research, 1998; 70(1): 25-37.

[28] Pedersen S, Sällvik K. Heat and moisture production at animal and house levels. 4th Report of Working Group on Climatization of Animal Houses. CIGR. Horsens, 2002.

[29] Rhodes C J. World meteorological organisation (WMO) report: Global greenhouse gas concentrations highest in 800,000-year record in 2016. Environment Reporter, 2017; 48(43): 1670.

[30] Wathes C, Holden M, Sneath R, White R, Phillips V. Concentrations and emission rates of aerial ammonia, nitrous oxide, methane, carbon dioxide, dust and endotoxin in UK broiler and layer houses. British Poultry Science, 1997; 38(1): 14-28.

[31] Besteiro R, Arango T, Rodríguez M R, Fernández M D, Velo R. Estimation of patterns in weaned piglets' activity using spectral analysis. Biosystems Engineering, 2018; 173: 85-92.

[32] Ngwabie N, Jeppsson K H, Gustafsson G, Nimmermark S. Effects of animal activity and air temperature on methane and ammonia emissions from a naturally ventilated building for dairy cows. Atmospheric Environment, 2011; 45(37): 6760-6768. 